\title{
Classification of Cesarean Sections in Small Private Maternity Hospitals as assessed by the Modified Robson Criteria (Canada)
}

Prasad L Bhanap

How to cite this article: Bhanap PL. Classification of Cesarean Sections in Small Private Maternity Hospitals as assessed by the Modified Robson Criteria (Canada). J South Asian Feder Obst Gynae 2017;9(1):68.

Source of support: Nil

Conflict of interest: None

Date of received: 15 November 2016

Date of acceptance: 25 December 2016

Date of publication: January 2017

\section{INTRODUCTION}

We read with interest the article titled "Classification of Cesarean Sections in Small Private Maternity Hospitals as assessed by the Modified Robson Criteria (Canada)" by Dr Atnurkar and Dr Mahale. ${ }^{1}$ We are impressed by two revelations: That some visiting surgeon is keeping a record of a very common (and, therefore, seemingly unimportant) surgical procedure for over 15 years (an example of great perseverance), and that the data relate to "Small Sole Proprietorship Type Hospitals." The publications from such hospitals are usually limited to case reports and some rare surgical procedures.

Rising rates of cesarean sections have become a matter of social criticism. Michael Robson's method of classifying cesarean sections definitely helps in indentifying a group, which, if addressed, because of its hugeness, might change the cesarean section rates. However, this classification is just the first step for those who wish to control the rising rate of cesarean section; hereafter, the problem is complex and solutions appear very difficult, if not impossible. Increasing safety of cesarean procedure, its widespread availability, and financial affordability of the family have also contributed to its rising rate. However, morbidity associated with it will always encourage practitioners to focus on its avoidance.

We have certain issues with this article. Were the authors only visiting surgeons at these hospitals? Does the number 7,342 include all cesarean sections from these hospitals, or are those done by other visiting surgeons not

\section{Professor}

Department of Obstetrics and Gynecology, IIMSR Medical College, Jalna, Maharashtra, India

Corresponding Author: Prasad L Bhanap, Professor Department of Obstetrics and Gynecology, IIMSR Medical College, Jalna, Maharashtra, India, e-mail: pbhanap@gmail.com included in this number? It might happen that with increasing seniority, the surgeon might be invited for only difficult cases or only repeat cesarean sections, and, in such cases, the data might not represent the actual happenings. Actual rates of cesarean section (number of cesarean sections per 100 live births) are also not available from this data.

Changing trends over these 15 years would have been more appreciated by the readers and could have helped in finding a solution if a significant difference was found.

The first four groups in this system of classification are for unscarred uteri with singleton vertex presentation. The total contribution of cesarean sections to these groups in this study ${ }^{1}$ and in the Raipur study ${ }^{2}$ is nearly the same, 59.4 and $54.46 \%$ respectively. This means to reduce contributions to first four groups, one must follow the Muscat ${ }^{3}$ way of managing pregnancies at term, which has $40.34 \%$ cases in this group. ${ }^{1}$

Group V is contributed by repeat cesarean sections. This and the two studies ${ }^{2,3}$ referred in this article do not provide any guidance as all have nearly the same contribution to this group. Vaginal birth after cesarean is the answer for this, but for various reasons it is avoided or practiced half-heartedly.

Thus, allowing a woman to become a multipara (of course with living healthy child) without a uterine scar is the trick for reducing cesarean section rates.

Groups VI and VII are high-risk cases as regards labor outcomes and are also small to bring about a major change in cesarean section rates.

We again appreciate the unique beauty of this article because of its duration of data collection and that from small private maternity hospitals. We suggest the authors to analyze their huge data to show changing trends over these years. We also are aware of authors' difficulty in getting data from similar settings for comparison.

\section{REFERENCES}

1. Atnurkar KB, Mahale AR. Classification of cesarean sections in small private maternity hospitals as assessed by the Modified Robson Criteria (Canada). J South Asian Feder Obstet Gynaecol 2016;8(2):107-112.

2. Abha S, Reema C. A recent way of evaluating cesarean birth. J Obstet Gynecol India 2009 Nov;59(6):547-551.

3. Kazmi T, Saiseema S 5th, Khan S. Analysis of cesarean section rate - according to Robson's 10-group classification. Oman Med J 2012 Sep;27(5):415-417. 